\title{
An Autopsy Study Conducted in Colombo South of Sri Lanka to Identify Average Sizes of Aortic and Mitral Valves of the Heart
}

Sathasivam R*, Vidanapathirana M

Department of Forensic Medicine, Faculty of Medical Sciences, University of Sri Jayewardenepura, Gangodawila, Nugegoda, Sri Lanka.

\begin{abstract}
Introduction: There was no uniformity in measuring the anthropological measurements of the heart in the literature. It varies from study to study, country to country, region to region within the same country and author to author according to the material and methodology of the study. So measurements of the heart also vary according to the methods used by different authors in their study. The normality standard for organ anthropometric measurements must be established in a specific reference sample for each population, as the normality values may be different under genetic and environmental influences. This study is aimed to determine the average size of mitral and aortic valves of the adult heart in autopsies done in Teaching Hospital, Colombo South of Sri Lanka. Assess the average circumferential length of the mitral and aortic and also determine the relationship with socio-demographic factors such as body weight, sex, and age and body length.

Methodology: This study was designed as a descriptive cross-sectional study done in fresh formalin unfixed adult hearts recovered from deceased died due to traumatic and unnatural causes. Samples were collected for one-year period between the periods of September 2018 to September 2019.

Results: Hundred and twenty-two (122) samples (68 males and 54 females) were included in this study among 282 adult hearts collected during this period due to strict inclusion and exclusion criteria. The average circumferential length of the mitral and aortic valves were in $\mathrm{cm}$ for male and females 9.49, 8.76 and 7.05, 6.88 .

Conclusion: This pilot study revealed that intermingling findings with western studies and eastern studies. Especially male mitral valve annular circumferences were compatible with western studies and other findings were compatible with eastern studies. A significant association was demonstrated in the circumference of MV with age and body length ( $\mathrm{p}$ value $=0.029,0.034$ ). We recommend large scales multi-centered studies to find out the normality standard for heart measurements in Sri Lankan population.
\end{abstract}

Keywords: Anthropology of heart, aortic valve, mitral valve, Colombo South of Sri Lanka

Received: 21 May 2021, Revised version accepted: 16 June 2021, Published: 30 June 2021. *Corresponding author: Raveendran S, $\triangle$ Email: sathasivamraveendran10@gmail.com, (D) https://orcid.org/0000-0002-2313-6491

Cite this article as: Sathasivam R*, Vidanapathirana M. An Autopsy Study Conducted In Colombo South of Sri Lanka to Identify Average Sizes of Aortic and Mitral Valves of the Heart. Medico-Legal Journal of Sri Lanka. 2021;9(1):7-13.

DOI: http://doi.org/10.4038/mljsl.v9i1.7437

Copyright: @ 2019 with the Medico-legal Journal of Sri Lanka.

This is an open-access article distributed under the terms of the Creative Commons Attribution 4.0 International License, which permits unrestricted use, distribution, and reproduction in any medium provided the original author and source are credited. 


\section{Introduction}

Cardiovascular disease is a well-known leading cause of sudden and unexpected death from natural pathology among adults not only in the world but also in Sri Lanka. Almost $80 \%$ of the causes for sudden and unexpected natural deaths were found within the cardiovascular system.[1] Structural and functional disturbances of the hearts can cause sudden death at any time during life.[1,2] Functional disturbances of hearts such as channelopathies like long QT syndrome, short QT syndrome, Brugadas syndrome, Wolff- Parkinson White syndrome and Catecholaminergic polymorphic ventricular tachycardia (CPVT) are very difficult to detect even after a meticulous autopsy.[2,3] Most of the structural and morphological disturbances of the heart can be detected scientifically by studying the anthropological measurements of the heart such as weight, wall thickness and valve sizes. $[4,5,6,7,8]$

Hearts with structural abnormalities are electrically unstable and can cause sudden death due to various mechanisms such as arrhythmias and pump failures.[1,2,3] Sometimes, such hearts are known to vulnerable to ischemia, infarction and even failure due to the imbalance between the oxygen demand and the blood supply.[1] Therefore, structural abnormalities of a heart may lead to functional disturbances causing sudden death at any point in life.[2] This entity is different from ischemic heart disease caused by coronary artery diseases. Most of the structural abnormalities of a heart can be detected with moderate accuracy by adapting anthropological measurements of the heart.[4] These methods are cost-effective and scientifically reliable if proper reference values are provided.

Third world countries including Sri Lanka lack expensive facilities such as electron microscope, immunohistochemistry and genetic testing can be benefited by this method if they do nationwide research to find out the normal reference values of quantitative measurements of the heart for the relevant population.

This research was conducted to assess the circumferential length of the mitral and aortic valves of the heart in autopsies done in Teaching Hospital, Colombo South to ascertain the variation with the demographic factors such as weight, age, sex, occupation and body length.

\section{Methodology}

This is a cross-sectional descriptive study, which was done in a prospective observational method. Medicolegal autopsy cases of sudden deaths from accidents, suicide, homicides and natural deaths from the non-cardiac origin that were brought to JMO's Office, Teaching Hospital, Colombo South during the period of one year from September 2018 to September 2019. Ethical authorization was approved by the Institutional Ethical Review Committee of Teaching Hospital, Colombo South (IERC, THCS) in September 2018.

Written informed consent of the legal claimant of the dead body had been obtained prior to obtaining information and anonymity had been maintained at all times, denoting each case only with a serial number. Though 282 samples of hearts were studied and analyzed, only 122 samples were included in this study for final data analysis due to strict inclusion and exclusion criteria. Age of the deceased being between 18-65 years, absence of putrefactive changes and the circumstances of the death being unnatural or anything natural with a non-cardiac origin were taken as inclusion criteria. The deceased being outside the aforesaid age range, deaths of those who are not Sri Lankans, bodies with evidence of putrefaction, presence of malnutrition or debilitating illnesses such as cancer, tuberculosis, chronic kidney diseases and the presence of cardiac pathologies such as hypertensive heart disease, valvular heart disease, ischemic heart disease, congenital heart disease and cardiomyopathy with structural disturbances were taken as exclusion criteria. Certain samples had to be removed from the study only after the discovery of histological evidence of cardiac pathologies including coronary atheroma or myocardial fibrosis.

The weight of the corpse was measured in the dorsal decubitus position, using an electronic platform weighing scale after removing all cloths, heavy ornaments and footwear. The length of the corpse was measured in the dorsal decubitus position, using an inelastic measuring tape from the top of the head (vertex) to the heel after removing the foot wear, taking into account the necessity to correct the height retraction due to the muscular contraction caused by the rigor mortis.

Gross findings at the autopsy including mitral valve and aortic valve were recorded in the printed pro forma at the autopsy. After dissection circumferential lengths of the valves were measured manually in $\mathrm{cm}$ by a flexible measuring scale along with the valve annular lines in the case of the mitral valve. Aortic valve measurements were taken at basal ring level by same $\mathrm{cm}$ scale.

Though assistance from two medico-legally trained doctors had been sought for collecting 
historical and clinical data, the dissection of the hearts, obtaining anatomical details and preparation and interpretation of histological slides were done by the investigators themselves. Haematoxylin and eosin slides were prepared from standard sections of the heart muscle and coronary vessels and histological evidence of significant coronary atherosclerosis and myocardial diseases such as myocarditis and myocardial fibrosis were excluded before selecting/including each case for the study. Though 282 cases were collected initially, only 122 had been selected for the study as the bulk of exclusions had taken place at the level of histological exclusion. Raw data collected on spreadsheets were shifted to an electronic format. Data were coded and entered in Microsoft Excel worksheets and analysed by using Statistical Package for Social Sciences (SPSS) version 21. Graphs and tables were used as appropriate to present the findings.

\section{Results}

Out of the initial 282 autopsies, only 122 cases fulfilled all criteria of selection for this study. Out of $122,68(56 \%)$ were male and $54(44 \%)$ were female. Thus the male:female ratio of $1.25: 1$ was observed. Ages ranged from 18 to 65 (mean age $42.25 \pm 14.99$ ) years. The majority was in the age group of 50-64 years $(n=46)$. The age and gender distribution are shown in Table 01.

\begin{tabular}{lrrr}
\hline $\begin{array}{l}\text { Age group } \\
\text { (years) }\end{array}$ & $\begin{array}{r}\text { Male } \\
\mathbf{N = 6 8} \\
\mathbf{n}(\boldsymbol{\%})\end{array}$ & $\begin{array}{r}\text { Female } \\
\mathbf{N = 5 4} \\
\mathbf{n}(\boldsymbol{\%})\end{array}$ & $\begin{array}{r}\text { Total } \\
\mathbf{N = 1 2 2} \\
\mathbf{n}(\boldsymbol{\%})\end{array}$ \\
\hline$<35$ & $20(16)$ & $24(20)$ & $44(36)$ \\
$35-49$ & $22(18)$ & $10(08)$ & $32(26)$ \\
$50-64$ & $26(21)$ & $20(16)$ & $46(38)$ \\
Total & $\mathbf{6 8}(\mathbf{5 6})$ & $\mathbf{5 4}(\mathbf{4 4})$ & $\mathbf{1 2 2}(\mathbf{1 0 0})$ \\
\hline
\end{tabular}

The average circumference values of mitral and aortic valves were $9.16 \pm 0.82 \mathrm{~cm}$ and $6.97 \pm 0.57$ $\mathrm{cm}$. The average circumference value of mitral and aortic valves in males was 9.49 and $7.05 \mathrm{~cm}$ and females were 8.76 and $6.88 \mathrm{~cm}$. Average circumferences of the valves in the heart with gender and age groups are shown in Table 02.

Table 02: Average circumferences of the valves in the heart with gender and age groups.

\begin{tabular}{lrrrr}
\hline $\begin{array}{l}\text { Age } \\
\text { group } \\
\text { years) }\end{array}$ & \multicolumn{2}{c}{$\begin{array}{c}\text { Average } \\
\text { circumferenc } \\
\text { e of } \mathbf{M V ~}(\mathbf{c m})\end{array}$} & \multicolumn{2}{c}{$\begin{array}{c}\text { Average } \\
\text { circumference } \\
\text { of } \mathbf{A V ~}(\mathbf{c m})\end{array}$} \\
\hline & Male & Female & Male & Female \\
\hline$<\mathbf{3 5}$ & 9.49 & 8.89 & 6.73 & 6.78 \\
$\mathbf{3 5 - 4 9}$ & 9.65 & 8.77 & 7.21 & 6.83 \\
$\mathbf{5 0 - 6 4}$ & 9.35 & 8.77 & 7.17 & 6.97 \\
Average & 9.49 & 8.76 & 7.05 & 6.88 \\
Total & & & & \\
Average & $\mathbf{9 . 1 6} \pm \mathbf{0 . 8 2}$ & $\mathbf{6 . 9 7} \pm \mathbf{0 . 5 7}$ \\
\hline
\end{tabular}

The distribution of the circumference value of mitral and aortic valves with the bodyweight among males and females is shown in Fig. 01.

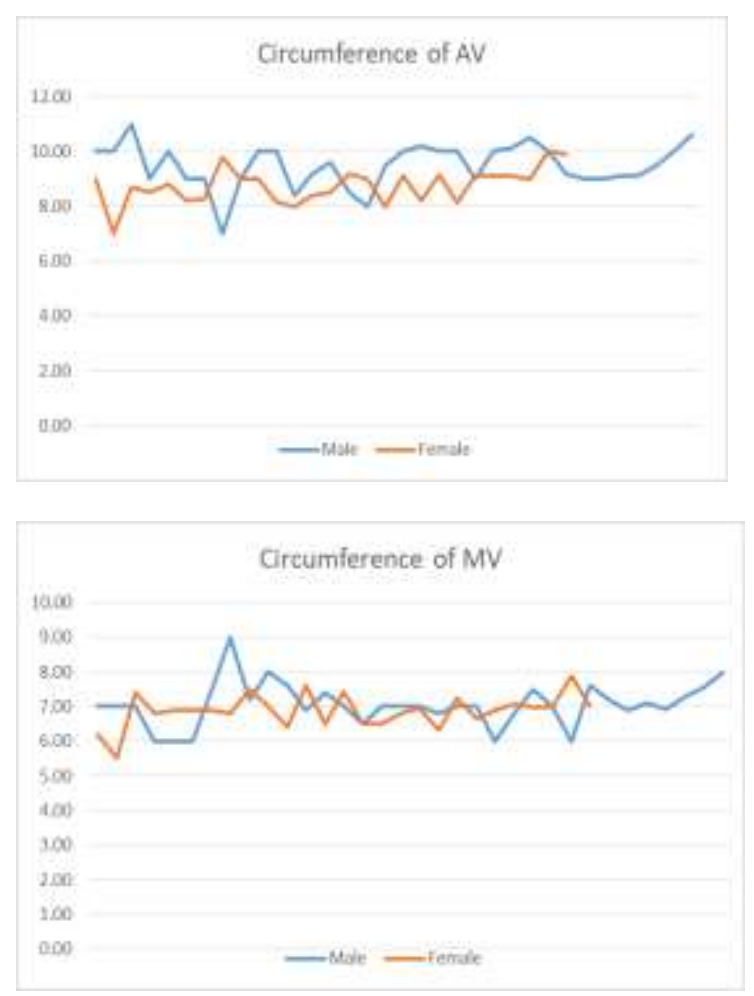

Figure 01. The distribution of the circumference value of mitral and aortic valves with the bodyweight among males and females

The weight in the range of $35.5 \mathrm{~kg}-102 \mathrm{~kg}$ (mean $-57.81 \pm 15.08 \mathrm{~kg}$ ). There was an increase in the circumference value of mitral and aortic valves with the weight distribution. The distribution of the circumference value of mitral and aortic valves with the bodyweight is shown in Fig. 02.

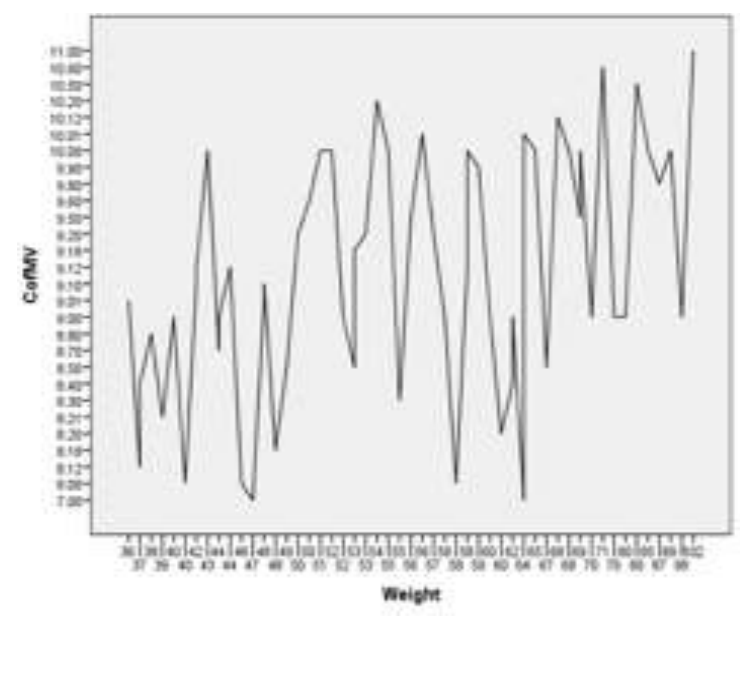




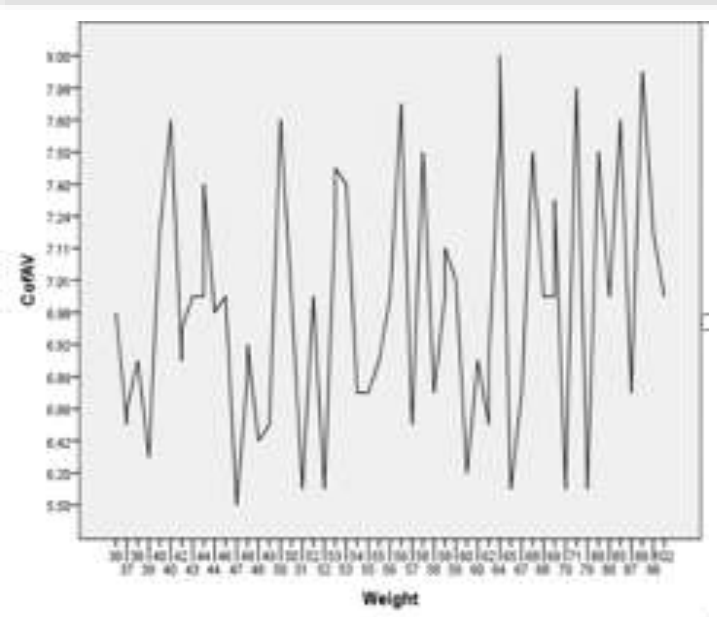

Figure 02. The distribution of the circumference value of mitral and aortic valves with the bodyweight

The length/height was in the range of $142-186 \mathrm{~cm}$ (mean 162.62 $\pm 9.51 \mathrm{~cm}$ ). There was an increase in the circumference value of mitral and aortic valves with the body length distribution. The distribution of the circumference value of mitral and aortic valves with the bodyweight is shown in Fig. 03.
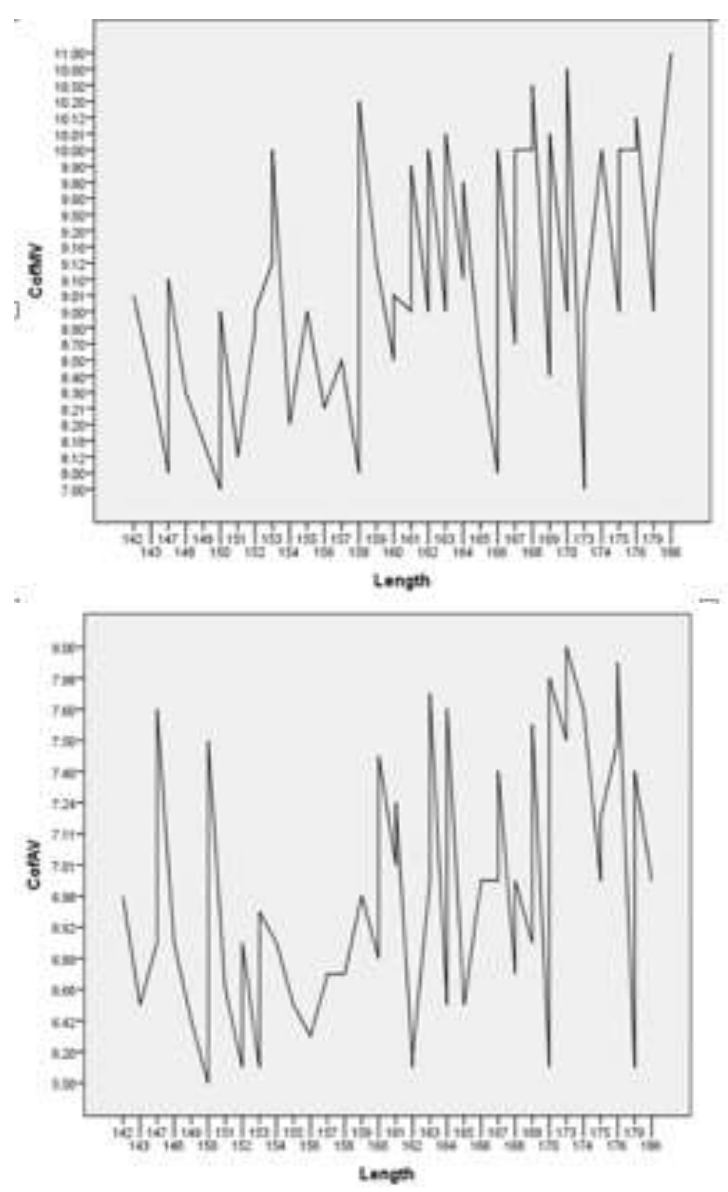

Fig. 3. The distribution of the circumference value of mitral and aortic valves with the bodyweight

Final analysis with Pearson chi-squares test revealed that there was significant correlation between the circumference of the mitral valve with age $(\mathrm{p}=0.029<0.05)$ and length $(\mathrm{p}=0.034<0.05)$. Other body parameters were failed to show a significant relationship with circumferences of mitral and aortic valves. Associations of heart valve measurements with other parameters are shown in Table 03.

Table 03: Pearson chi-square test for association of heart valve measurements with other parameters

\begin{tabular}{lrrr}
\hline $\begin{array}{l}\text { Association of } \\
\text { Parameters }\end{array}$ & $\begin{array}{r}\text { Chi } \\
\text { square }\end{array}$ & $\mathbf{X}^{\mathbf{2}}$ & $\begin{array}{r}\text { Associat } \\
\text { ion (p } \\
\text { value) }\end{array}$ \\
\hline $\begin{array}{l}\text { Circumference of } \\
\text { MV with gender }\end{array}$ & 29.992 & 27 & 0.315 \\
$\begin{array}{l}\text { Circumference of } \\
\text { MV with age }\end{array}$ & $\mathbf{9 7 2 . 5 7 7}$ & $\mathbf{8 9 1}$ & $\mathbf{0 . 0 2 9}$ \\
$\begin{array}{l}\text { Circumference of } \\
\text { MV with weight }\end{array}$ & 1392.325 & 1350 & 0.206 \\
$\begin{array}{l}\text { Circumference of } \\
\text { MV with length }\end{array}$ & $\mathbf{9 1 3 . 2 2 1}$ & $\mathbf{8 3 7}$ & $\mathbf{0 . 0 3 4}$ \\
$\begin{array}{l}\text { Circumference of } \\
\text { AV with gender }\end{array}$ & 38.737 & 28 & 0.085 \\
$\begin{array}{l}\text { Circumference of } \\
\text { AV with age }\end{array}$ & 941.467 & 924 & 0.338 \\
$\begin{array}{l}\text { Circumference of } \\
\text { AV with weight }\end{array}$ & 1300.224 & 1400 & 0.973 \\
$\begin{array}{l}\text { Circumference of } \\
\text { AV with length }\end{array}$ & 884.884 & 868 & 0.338 \\
\hline
\end{tabular}

\section{Discussion}

Our study is a cross-sectional prospective descriptive study which was done in 122 heart samples recovered from deceased who died due to traumatic and unnatural external causes with the manner of homicide, suicide and accidents in the category.

The normality standard for organ anthropometric measurements must be established in a specific reference sample for each population, as the normality values can be different under genetic and environmental influences.[9] This fact is corroborated by the study of Dadgar et al, which, after the examination of 100 bodies with no cardiac abnormalities, reported that the mean total weight of the Indian hearts was lower than that reported in the literature for other racial groups.[10]

The average circumferential value of the aortic valve was $6.97 \pm 0.57 \mathrm{~cm}$ in our samples and mean 
values were slightly high in males $(7.05 \pm 0.11 \mathrm{~cm})$ and low in females $(6.88 \pm 0.93 \mathrm{~cm})$. The average values of our sample were almost the same to the Caucasian and slightly higher than the Indians.[11,12] Values for Caucasians were between $6.92 \pm 0.69 \mathrm{~cm} .[11]$ Another study reported that the mean aortic annular circumference at (add the) basal ring in $10 \%$ formalin preserved adult Caucasians was $7.28 \pm$ $0.92 \mathrm{~cm} .[13]$

Another study was done in Sri Lanka by Uthaya Kumar et al 320 fresh, autopsied, normal, adult, Sri Lankan hearts collected from the Office of the Judicial Medical Officer, National Hospital of Sri Lanka (NHSL).[14] The mean aortic root circumference at the basal ring was $64.7 \pm 7 \mathrm{~mm}$ (males $66.0 \pm 6.4 \mathrm{~mm}$, females $58.0 \pm 6.1 \mathrm{~mm}$ ). [14] These values are lower than -our values. Their study had further revealed that mean circumference showed significant gender difference. But there is no significant gender difference in our study. A significant positive correlation was seen between the age and aortic root circumference in that study. But no association was seen in our study except in males. There is an increase in aortic valve circumference after the age of 35 years in males. However, in the above study conducted at the NHSL, the dead bodies had not been measured.

Aortic valve size is significantly reducing after the age of seventy due to ageing and calcification.[15] This cannot be demonstrated in our study due to our samples were collected from the decreased age less than 65 years. Aortic valve sclerosis is present in approximately $20-30 \%$ of individuals aged over 65 years and in $48 \%$ of patients over 85 years, while significant stenosis affects $2-3 \%$ of those over 65 years of age and up to $8 \%$ of those over 85 years.[16,17] The aortic valve ring begins to dilate, paralleling the changes in elasticity and this dilatation is a true ageing process and the most frequent cause of non-valvular forms of aortic valvular regurgitation in the elderly.[18]

This fact should be considered in selecting the valve sizes in aortic valve replacement surgeries and interpretation of aortic valve sizes in magnetic resonance imaging (MRI) and echo cardio-graphic studies and in postmortem studies in deceased with congenital/acquired aortic valvular disease (Mild to severe aortic stenosis and aortic regurgitation).

The average circumferential value of the mitral valve was $9.16 \pm 0.82 \mathrm{~cm}$ in our study samples and mean values were slightly high in males $(9.49 \pm$ $0.14)$ and low in females $(8.76 \pm 0.13)$. There is no significant increase/ reduction in the size of mitral valves in both sexes in relation to age. Circumferences of Mitral valves by studies and methods were summarized below for comparison with our values.

\begin{tabular}{|c|c|c|c|}
\hline $\begin{array}{l}\text { Study } \\
\text { performed }\end{array}$ & $\begin{array}{r}\text { Average } \\
\text { values-cm }\end{array}$ & $\begin{array}{r}\text { Sample } \\
\text { size }\end{array}$ & Method \\
\hline Present study & $\begin{array}{r}9.49 \text { in males } \\
8.76 \text { in females }\end{array}$ & 122 & $\begin{array}{r}\text { Dissection } \\
\text { method }\end{array}$ \\
\hline $\begin{array}{l}\text { Ranganathan } \\
\text { et al }{ }^{[19]}\end{array}$ & $\begin{array}{r}9.0 \text { in male } \\
7.2 \text { in female }\end{array}$ & 50 & $\begin{array}{r}\text { Dissection } \\
\text { method }\end{array}$ \\
\hline Gunal et al ${ }^{[20]}$ & $\begin{array}{r}9.12 \pm 1.36 \text { in } \\
\text { both }\end{array}$ & 116 & $\begin{array}{r}\text { Dissection } \\
\text { method }\end{array}$ \\
\hline Guptha et $\mathrm{al}^{[21]}$ & $\begin{array}{r}9.11 \pm 0.44 \mathrm{~cm} \\
\text { in both }\end{array}$ & 18 & $\begin{array}{r}\text { Dissection } \\
\text { method }\end{array}$ \\
\hline S A & 10.7 in males & - & Dissection \\
\hline $\begin{array}{l}\text { Cheema }^{[2]} \\
\text { Omriston et al } \\
{[23]}\end{array}$ & $\begin{array}{l}9.16 \text { in females } \\
9.3 \pm 0.9 \text { in both }\end{array}$ & 11 & $\begin{array}{l}\text { method } \\
2 \mathrm{D} \text { Echo }\end{array}$ \\
\hline Amgain et al & $\begin{array}{r}8.03 \pm 0.8 \text { in } \\
\text { both }\end{array}$ & 50 & Cardiac sizer \\
\hline
\end{tabular}

A significant positive relationship exists between the mitral annular circumference (MAC) with age, height and body surface area of the person $(\mathrm{P}<0.05)$ was mentioned by Uthayakumar et al.[25] The mean size of the MAC was $94.41 \pm 5.9$ $\mathrm{mm}$ in males and $84.62 \pm 8 \mathrm{~mm}$ in females and the difference was statistically significant $(\mathrm{P}<0.001)$. Our results of the circumference are almost comparable with those reported by her in males and females and no significant positive correlation in our study with weight, age and height. It may be due to the lesser number of samples and also to the outliers in our samples. Her study was done in a total of 319 (267 males and 52 females) normal adult fresh autopsied hearts with ages ranging from 18-72 years at the University of Colombo. At the end of that comprehensive study author highlights that the measurements of Mitral circumference in Sri Lankans are smaller than that of Caucasians even though it was done in a single center. But we prefer to have a large-scale multi-centered study with proper sampling method to determine the mitral annulus circumference in the adult SriLankan population.

Mitral valve size measurement in North Karnataka by using cardiac sizer in $10 \%$ formalin-fixed fifty adult cadaveric hearts without any obvious pathology were obtained from the Department of Anatomy, Jawaharlal Nehru Medical College, Belgaum revealed that the mean annular circumference and diameter of the mitral valve was found to be $8.03 \pm 0.82 \mathrm{~cm}$. The majority (72\%) of the mitral valves had a circumference ranging from 7.53 to $8.47 \mathrm{~cm}$ in his study. [24] These values are lesser than our study. This difference may be due to the difference in method and material between our study and their study. 
A study done by dissection method in Maharashtra showed that the average circumference of the mitral valve is $9.34 \mathrm{~cm}$. [26] Total of 30 cadaveric hearts were included in this study. This value is almost equal to our study. Rajathi et al reported that the mean mitral valve circumference value is $8.86 \pm 0.16 \mathrm{~cm}$ according to the study done in sixty adult cadaveric hearts in Chennai, India. [27] This value is also near to our mean values. Another study was done by Shakthivel et al reveals that the average circumference of the annulus was found to be $8.29 \mathrm{~cm}$ South Indian.[28] Mitral circumference value is $7-11 \mathrm{~cm}$ in normal Caucasian, but it can be dilated up to $8-18 \mathrm{~cm}$ in the case of dilated cardiomyopathy. [29]

In this study, significant associations were demonstrated in the circumference of MV with age and body length $(\mathrm{p}$ value $=0.029,0.034<0.05)$.

\section{Conclusion and recommendations}

The present study gives detailed knowledge of the mitral and aortic valve measurements in a subset of the Sri Lankan population who were residing in or near Colombo South. This study gives values of the average size of the mitral and aortic valve of the adult heart in autopsies done in Teaching Hospital, Colombo South. This study also ascertains the variation of heart measurements with demographic factors such as weight, age, and sex and body length. We hope that data regarding the normal heart measurements presented here would serve as a baseline data for further studies in the Sri Lankan population and also in the population of other countries for comparison values. It also minimizes the errors which can be created by using western and other regional values in clinical and autopsy cases. Anatomical measurements, understanding the pathophysiological mechanisms and appropriate interpretation of these reference values with age, sex, body weight and body length helps the cardiothoracic surgeons in treating patients suffering from various cardiac and valvular pathologies, clinical cardiologist in doing echo and cardiac MRI and also in designing appropriate size cardiac and valvular prosthesis. And also, it is important in interpreting the values in autopsy studies for accurate diagnosis of congenital and acquired cardio-vascular disorders or diseases affecting the cardio-vascular system.

We recommend large scales studies in the future to minimize the errors and to increase the internal validity of the study to get more accurate values and also recommend multi-centered studies to increase the external validity of the study. It will help to formulate proper and accurate reference values for Sri Lankan population.

\section{Acknowledgments}

Consultants, Doctors, staff and mortuary workers of JMO's Office of the Colombo South Teaching Hospital for the incredible support during the data collection. Ms. Sathana Paramanathan, Research Assistant, the University of Jaffna for her valuable contribution in the process of analyzing the data.

\section{Disclosure statement}

Ethics and Consent- Research was conducted with the consent of next of kin. No intervention was done in cadavers for research purposes.

Conflicts of interests: The author declares that she has no conflicts of interest.

Funding: None

\section{References}

1. Frederick JS, Richard NM. The heart. In: Robbins and Cotran Pathologic basis of disease. 1st ed. India: Thomson Press 1td; 2015. pp.523-78

2. Saukko P, Knight B. The pathology of sudden death. In: Knight's Forensic Pathology.4th ed. New York: CRC press; 2016. pp. 515-52

3. DiMaio VJ, DiMaio D. Death due to natural diseases, Forensic Pathology, 2nd ed. New York: CRC press; 2001. pp. 64-80

4. Umadethan B. principles and practice of Forensic Medicine. 2nd ed. India: CBS Publishers; 2016.

5. Kitzman DW, Scholz DG, Hagen PT, Ilstrup DM, Edwards WD. Age-related changes in normal human hearts during the first 10 decades of life. Part II (Maturity): A quantitative anatomic study of 765 heart specimens from subjects 20 to 99 years old. Mayo Clin Proc. 1988; 63(2):137-46

6. Rosahn PD. The Weight of the Normal Heart in Adult Males, Yale J Biol Med. 1941 Dec;14(2):209-

23.https://www.ncbi.nlm.nih.gov/pmc/article s/PMC2601062

7. Richard NM. Blood vessels. In: Robbins and Cotran Pathologic basis of disease. 1st ed. India: Thomson Press ltd; 2015. pp. 483-22

8. Sampson BA, Adams VI, Hirsch CS. Sudden and unexpected death from natural causes in adults. In: Spitz and Fisher's Medico-legal investigation of death.4th ed. U.S.A: Charles C Thomas Publishers Ltd; 2005. pp.301-42

9. Grandmaison GL, Clairand I, Durigon M. Organ weight in 684 adult autopsies: new tables for a Caucasoid population. Forensic Sci Int. 2001 Jun 15;119(2):149-54. doi: 
10.1016/s0379-0738(00)00401-1. PMID: 11376980.

10. Dadgar SK, Tyagi SP, Singh RP, Hameed S. Factors influencing the normal heart weight-a study of 140 hearts. Jpn Circ J. 1979 Feb;43(2):77-82. doi: 10.1253/jcj.43.77. PMID: 449022.

11. Berdajs D, Lajos P, Turina M. The anatomy of the aortic root. Cardiovasc Surg. 2002 Aug;10(4):320-7. doi: 10.1016/s09672109(02)00018-2. PMID: 12359401.

12. Sahni D, Indarjit. Size of the valves and thicknesses of anterior walls of the ventricles of the adult Indian hearts. Indian Heart J. 1991 Sep-Oct;43(5):361-5. PMID: 1820998.

13. Westaby S, Karp RB, Blackstone EH, Bishop SP. Adult human valve dimensions and their surgical significance. Am J Cardiol. 1984 Feb 1;53(4):552-6. doi: 10.1016/00029149(84)90029-8. PMID: 6229998.

14. Udhayakumar S, Yasawardene SG. Aortic annular measurements in fresh post-mortem hearts; a study in Sri Lankans. Ceylon Med J. 2015 Dec; 60 (4):148-51. doi: 10.4038/cmj.v60i4.8222.

15. Gómez MMI, Betancor IH, Niebla JG, López BM, Cerdeña IL, Almeida JL. Valve Calcification in Aortic Stenosis: Etiology and Diagnostic Imaging Techniques. Biomed Res Int. 2017;2017:5178631. doi: 10.1155/2017/ 5178631. PMID: 28812017

16. Lindroos M., Kupari M., Heikkila J., Tilvis R. Prevalence of aortic valve abnormalities in the elderly: an echocardiographic study of a random population sample. Journal of the American College of Cardiology. 1993;21(5):1220-5. doi: 10.1016/07351097(93)90249-z.

17. Stewart B. F, Siscovick D., Lind B. K. Clinical factors associated with calcific aortic valve disease. Journal of the American College of Cardiology. 1997;29(3):630-4. doi: 10.1016/S0735-1097(96)00563-3.

18. Sawabe M, Hamamatsu A, Chida K, Mieno MN, Ozawa T. Age is a major pathobiological determinant of aortic dilatation: a large autopsy study of community deaths. J Atheroscler Thromb. 2011;18(2):157-65. doi: 10.5551/jat.6528.

19. Ranganathan TS. The heart, Textbook of Human Anatomy, 6th Edition, S. Chand \& Co., 2010, p-435.
20. Gunnal SA, Farooqui MS, Wabale RN. Study of mitral valve in human cadaveric hearts. Heart Views. 2012 Oct;13(4):132-5. doi: 10.4103/1995-705X.105729. PMID: 23439693 ; PMCID: PMC3573357.

21. Gupta C, Shetti, VR, Manju, BVM. Dimensions of the human adult mitral valve in the embalmed cadaver. J.Morphol.Sci.,2013; 30(1):6-10.

22. Shamim Akthar Cheema, Anjum Jalal, Naseem Feroze, Jawad Sajid Khan, Dimensions of Mitral Valve of Normal Human Hearts In Pakistani Subjects 1996;29:3-4.

23. Ormiston JA, Shah PM, Tei C, Wong M. Size and motion of the mitral valve annulus in man. I. A two-dimensional echocardiographic method and findings in normal subjects. Circulation. 1981 Jul;64(1):113-20. doi: 10.1161/01.cir.64.1.113. PMID: 7237707.

24. Amgain K, Thakur SK, Virupaxi RD, Dixit D, Desai SP, Gan M. Mitral valve size measurement in North Karnataka by using cardiac sizer: A cadaveric study. Arch Med Health Sci 2013;1:105-8. DOI: 10.4103/23214848.123016

25. Udhayakumar S, Yasawardene SG. Fresh autopsy study of dimensions of adult mitral valve in Sri Lankans. Peradeniya Univ. International Research Sessions 2014(18), P 275 http://dlib.pdn.ac.lk/handle/1/4818

26. Pant P, Mukhia R, Kumari HN, Mukherjee A. Morphological and morphometric analysis of mitral valve in Maharashtra region: Cadaveric study. Indian J Appl Res 2013;3:497-8. https://www.worldwidejournals.com/indianjournal-of-applied-research

27. Charanya N, Rajathi G, Vishali N Morphological and morphometrical analysis of mitral valve annulus of heart in human adult cadavers. Int $J$ Anat Res 2017;5(3.3):44054409. DOI: 10.16965/ ijar.2017.350

28. Ilankathir S, Sakthivel S. Morphometry of Mitral Valve in South Indians - A Cadaveric Study; National Journal of Basic Medical Sciences 2017;8(1):5-9

29. Dal-Bianco JP, Levine RA. Anatomy of the mitral valve apparatus: role of $2 \mathrm{D}$ and $3 \mathrm{D}$ echocardiography. Cardiol Clin. 2013 May;31(2):151-64. doi: 10.1016/j.ccl.2013. 03.001 PMID: 23743068 